\title{
Research Paper: The Effects of National Academy of Sports Medicine and Sahrmann Training on Foot Pressure Distribution in Flexed Posture Students
}

\author{
Karim Mohammad Jabbar' ${ }^{1}$, Farzaneh Gandomi ${ }^{1 *}$ (D)
}

1. Department of Sport Injuries and Corrective Exercises, Faculty of Physical Education and Sport Sciences, Razi University, Kermanshah, Iran.

\begin{tabular}{|c|c|}
\hline $\begin{array}{l}\text { Use your device to scan } \\
\text { and read the article online }\end{array}$ & Citation: Mohammad Jabbar K, Gandomi F. The Effects of National Academy of Sports Medicine and Sahrmann Train- \\
\hline 口ifiris & $\begin{array}{l}\text { ing on Foot Pressure Distribution in Flexed Posture Students. Iranian Rehabilitation Journal. 2021; 19(1):99-110. http://dx.doi. } \\
\text { org/10.32598/irj.19.1.1319.1 }\end{array}$ \\
\hline 目5 & doi'http://dx.doi.org/10.32598/irj.19.1.1319.1 \\
\hline
\end{tabular}

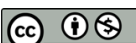

Article info:

Received: 09 Jan 2021

Accepted: 30 Mar 2021

Available Online: 01 Mar 2021

\section{Keywords:}

Hyperkyphosis, posture, exercise, foot, kyphosis, postural control

\begin{abstract}
Objectives: Flexed posture with Hyperkyphosis (HKP) and Forward Head Posture (FHP), due to changes in the spine alignment, lead to the displacement of the center of pressure and increased postural sways; ultimately, this condition disrupts the distribution of foot pressure. Therefore, the present study aimed to compare the effects of 8 weeks of National Academy of Sports Medicine (NASM) and Sharman training on Foot Pressure Distribution (FPD) in flexed posture students.
\end{abstract}

Methods: In this double-blind randomized clinical trial, 30 students with HKP and FHP were randomly assigned in two groups of NASM and Sahrmann ( $n=15$ /group). The angle of HKP and FHP were evaluated by Spinal Mouse and Image J software. FPD was also assessed by a Payatek foot scaner (PT-scan) device. The obtained data were analyzed in SPSS using one-way Analysis of Covariance (ANCOVA).

Results: The present research results suggested that both intervention groups presented significant differences in reducing the angle of HKP $(\mathrm{P}<0.001)$ and FHP $(\mathrm{P}<0.001)$, COP minor axis length $(\mathrm{P}<0.05)$, COP major axis length $(\mathrm{P}<0.001)$, COP path length $(\mathrm{P}<0.001)$, the standard deviation of internal-external sways $(\mathrm{P}<0.001)$, and standard deviation of anteriorposterior sways $(\mathrm{P}<0.001)$; however, $\mathrm{t}$ there was no significant difference concerning the $\mathrm{COP}$ area $(\mathrm{P}>0.05)$ and symmetry index between the two legs $(\mathrm{P}>0.05)$.

Discussion: Both provided corrective exercises reduced HKP and FHP angles and reduced postural sways. However, Sahrmann intervention with adjusted muscle stiffness and reduced electromechanical latency was more effective than NASM exercises in improving postural control and foot pressure symmetry index.

\section{* Corresponding Author:}

Farzaneh Gandomi, PhD.

Address: Department of Sport Injuries and Corrective Exercises, Faculty of Physical Education and Sport Sciences, Razi University, Kermanshah, Iran. Tel: +98 (83) 34283270

E-mail: gandomi777@gmail.com 


\section{Highlights}

- Both NASM and Sahrmann corrective exercises reduced HKP and FHP angles and postural sways.

- Sahrmann intervention was more effective than NASM in improving postural control.

- Sahrmann intervention was more effective than NASM in improving foot pressure symmetry index.

\section{Plain Language Summary}

Flexed posture is defined as Hyperkyphosis (HKP) and Forward Head Posture (FHP), i.e., highly prevalent in students. Changes in the spine alignment lead to the displacement of the center of pressure and increased postural sways; ultimately, this condition disrupts the distribution of foot pressure. This study examined the effects of two types of corrective exercises (NASM vs. Sahrmann) on foot pressure distribution. The relevant results suggested that Sahrmann intervention was more effective than NASM exercises in improving postural control and foot pressure symmetry index.

\section{Introduction}

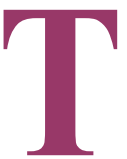

echnological advancements and the use of social media and computers have led to limited mobility and the prevalence of spinal deformities [1]; accordingly, $53 \%$ of students have reported musculoskeletal disorders due to the long-term use of computers [2]. One of the most prevalent types of poor postures is flexed posture. In this condition, thoracic Hyperkyphosis (HKP) and Forward Head Postures (FHP) occur simultaneously. This condition can adversely affect the biopsychological aspects of individuals' lives [1]. HKP refers to a kyphotic angle $>40^{\circ}$ $45^{\circ}$ and is among the most common poor postures [3]. The degree of normal kyphosis was reported as 42 for 18- to 28-year-olds in Iran [4]. According to the Janda approach, deformity in one part of the body affects other regions and leads to malalignments [5]. According to previous studies, individuals with thoracic HKP have FHP; the cause of which is a compensatory mechanism to align eye direction with the horizon [6]. However, the prevalence of FHP was reported in the range of $66 \%$ $80 \%$ [7]. Generally, FHP occurs when the Craniovertebral Angle (CVA) is $>50^{\circ}$. Secondarily, this condition causes some musculoskeletal disorders, such as neck pain, headache, and chewing difficulties [8].

Postural control that stabilizes the body in space by integrating sensory input about body position with motor output to coordinate the action of muscles and keep the body's Center of Mass (COM) within its base of support is critical and may be affected by poor postures [9]. Overall, any change in the normal status of the spine disturbs postural control. Accordingly, various studies have reported postural control disorder in individuals with HKP and FHP [10-12]. In this condition, the COM is transferred forward, a change in the natural function of proprioception; muscle spindles; articular mechanical receptors, and weakness in the endurance and strength of back muscles. Such conditions lead to a postural control disorder, that was previously documented by Navega et al. [13] and Jang et al. [14]

In FHP, the head is transferred to the front, autolytic organs, and the position of the eyes changes relative to the horizon; consequently, it results in poor postural control and increased postural sways [11]. Given the direct relationship between cervical afferents and vestibular and balance systems, any morphological change in cervical spine muscles and skeletal muscles might generate postural control disorders [1]. This finding was supported by Kang and associates [10]. Furthermore, a change in the center of gravity and a subsequent postural control disorder leads to the disturbance of plantar pressure distribution. This is mainly because maintaining balance depends on the plantar pressure distribution. Besides, a change in postural alignment (e.g., HKP) can potentially affect these loading patterns, i.e., approved by Mousavi et al. [15] and Kim et al. [16] in individuals with HKP and FHP, respectively.

The American National Academy of Sports Medicine (NASM) presented a 4-step corrective exercise protocol. This program includes the following: first: inhibition, which uses the self-mobilization release technique; second: lengthening, which applies the stretching technique; third: activation, which uses the strengthening technique, and the fourth step: integration [17], i.e., become common recently. Besides, Sahrmann attempted to introduce 
movement impairment syndromes to describe conditions that can be diagnosed and treated by physiotherapists. Sahrmann believes that the source of musculoskeletal disorders is the imbalance of muscle stiffness between the agonist and antagonist muscle groups [18].Most studies used NASM exercises and the corrective protocols by Sahrmann are less employed in this area. Thus, we aimed to compare the effects of the two methods of NASM and Sahrmann corrective exercises on HKP and FHP correction, Plantar Pressure Distribution (PPD), and Postural Control (PC) in students with flexed postures.

\section{Methods}

The present double-blind randomized clinical trial was performed on students with HKP and FHP. The study participants were selected from the students of Razi University in Kermanshah City, Iran. Accordingly, their condition was confirmed by a corrective exercise specialist. First, the research objectives, tools, and assessment process were explained to the study participants. Furthermore, a written informed consent form was obtained from the study subjects to attend corrective exercises laboratory and therapeutic sessions.

The explored students aged in the range of 18-25 years and were diagnosed with HKP and FHP at Razi University. In total, 12 subjects were required to satisfy a significance level of 0.05 with the power of 0.95 , and an effect size of 0.61 [19] (G-power software 3.1.2; Franz Faul, University of Kiel, Kiel, Germany). Considering the odds of sample dropout, a total of 30 subjects were selected and divided into two groups of 15 (Sahrmann \& NASM groups). First, possible FHP and HKP cases were determined in the study participants through visual assessment, followed by a more accurate evaluation. The inclusion criteria of the study were the lack of pain in the shoulder girdle, back, neck, or upper extremity; a history of shoulder and neck injury; the lack of other deformities; an HKP angle of $>45^{\circ}[14]$; and an FHP angle of $>47^{\circ}$ [16]; the age range of 18-25 years; proving written informed consent forms; the lack of consumption of any drugs that could affect postural control, as well as the lack of unmanageable neurological and skeletal conditions. The exclusion criteria included no pathological symptoms related to the history of fracture, surgery, or joint diseases of the spine; pain in lower or upper extremities; practicing regular exercise activities; the deformity of the lower extremity or trunk; a history of imbalance, severe pain in joints of the lower extremity and trunk, and participation in physiotherapy sessions [20] (Figure 1).
A list of numbers was provided by the random number allocation software; each of which was randomly assigned to the interventions based on Sahrmann and NASM corrective exercises. Next, the NASM or Sahrmann corrective exercise interventions were assigned to each study participant based on their recruitment order. Accordingly, a fixed-size design with the concealed allocation ratio of 1:1 was used for randomization.

The subjects of which were blind to their allocation to research groups and the existence of another group. Moreover, the corrective exercise laboratory specialist was blinded to research goals, the allocation of groups, and the exercise protocols.

All study variables were performed before and after conducting the 8-week correction protocol in the corrective exercise laboratory of the Razi University by the head of the laboratory.

The HKP angle was assessed using the Spinal Mouse Device, which had favorable validity $(\mathrm{r}=0.94)$. Moreover, its intra- and inter-group reliability were reported as $\mathrm{ICC}=0.92$ and $\mathrm{ICC}=0.79$, respectively. First, the examiner determined the seventh Cervical Vertebrae (C7) and the second sacral bone (S2) manually and marked those. Followed participants were requested to stand naturally, arms were hanging at the side of the body, knees were in full extension, and legs were shoulder-width apart. Then, the Mouse of Spinal Device was placed on C7 and extended to S2 (Figure 2a) [21, 22].

The photography and Image $\mathrm{J}$ software was used to measure the angle of FHP, $(\mathrm{ICC}=0.92)$. The study subject was placed in a side view, and the tragus and the spinous process of $\mathrm{C} 7$ were marked. Then, the research subject was requested to stand at a $23-\mathrm{cm}$ distance from the wall where their right arm was toward the wall. Subsequently, a digital camera was placed $265 \mathrm{~cm}$ away from the wall at a height equal to the study subject's left shoulder. Besides, the study participant was requested to raise their hands above their head, stand in a natural and comfortable position, and look in front of them. An image was captured after a five-second pause. It was then uploaded on Image J software to determine the angle between the line linking the tragus to $\mathrm{C} 7$ with the line perpendicular to the angle of the head forward (Figure 2b) [20].

We assessed the variables associated with foot pressure distribution. The required data were collected using a plantar pressure distribution device (PT-scan, Payatek, Mashhad, Made in Iran). The device has a monitor screen and a pressure measuring screen with an area of 


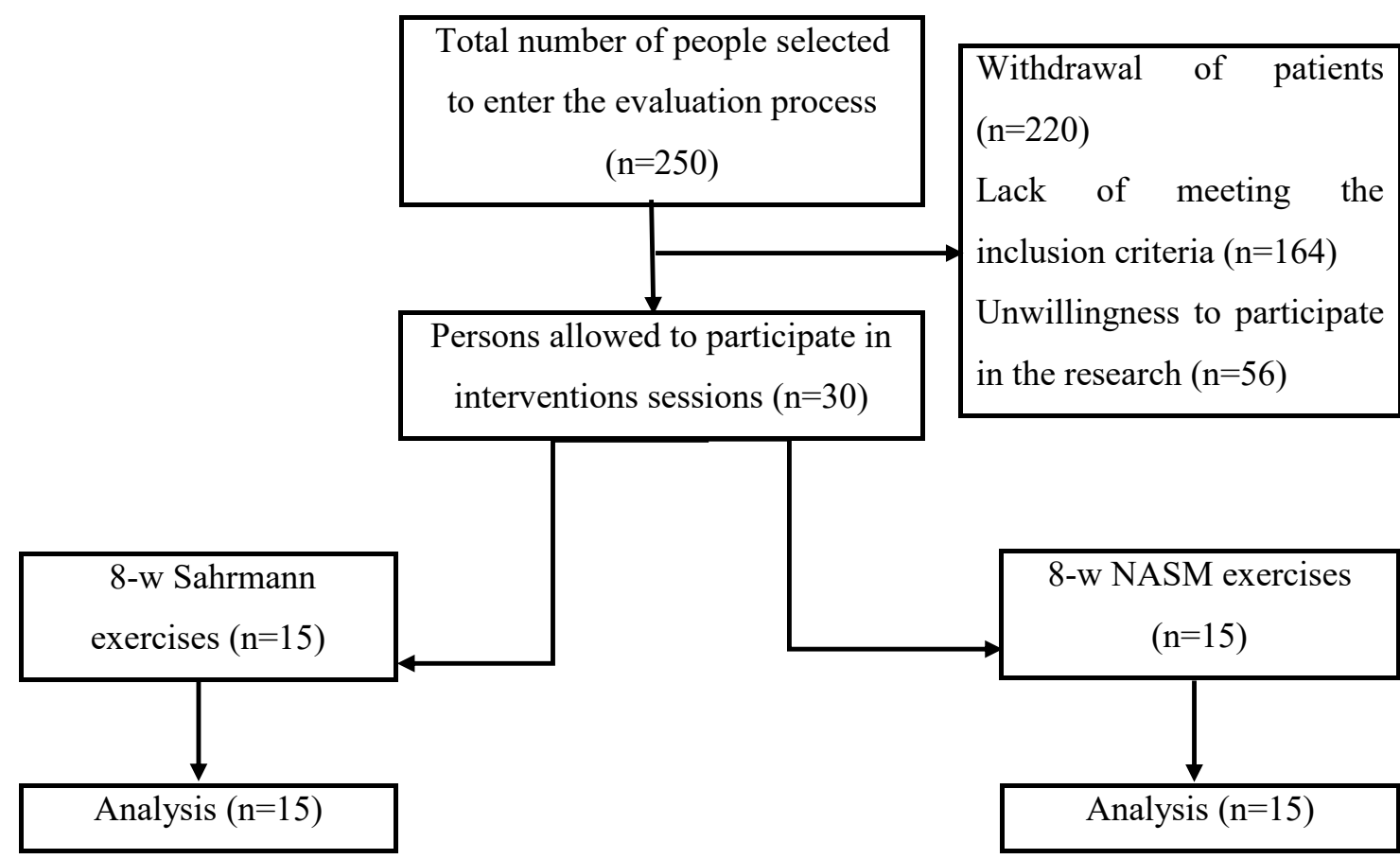

Figure 1. Subject selection process

Iranian Rehabilitation Journal

$50 \times 50 \mathrm{~cm}^{2}$ with 2300 sensors and a sampling frequency of $165 \mathrm{~Hz}$. With the guidance of the laboratory director, the study subjects stood on the plantar pressure device plate bare feet with hands hanging by their sides. The research participants were taught to look at the marked point, i.e., two meters away on the wall and adjusted according to their height. Overall, 20-second tests were performed 3 times with a two-minute rest between them. Besides, the mean score of the 3 replications was determined as the final data for statistical analysis [23]. Equation 1 was used to measure the plantar symmetry index between two feet; Equation 2 was applied to measure the symmetry index between the front and back of the foot, and measurements were conducted in Excel [23].The software's outputs included Minor Axis Length, Major Axis Length, COP path length, the standard deviation of internal-external sways, and the standard deviation of anterior-posterior sways (Figure 3).

\section{1: $S I=\frac{\text { Right pressure }}{\text { Right pressure }+ \text { Left pressure }}$ \\ 2: $S I=\frac{\text { Forward pressure }}{\text { Forward pressure }+ \text { Backward pressure }}$}

The NASM and Sahrmann corrective approaches were used for the study participants for 8 weeks, 3 sessions a week, and one hour per session ( 5 minutes of warmup +50 minutes of corrective exercises +5 minutes of cool-down). The process of implementing corrective interventions is described below in detail.

The NASM corrective exercises were performed in 4 steps of inhibition, lengthening, activation, and integration. The first step was conducted using foam rolls to relieve tension for the tight muscles [17]. The study participants applied foam rolls to the desired area for 30 seconds. In the second step, key lengthening exercises were performed through static stretching for the tight muscles. Stretching techniques were performed with 3 sets of 20-30 seconds. In the third step, strengthening exercises were carried out on weak muscles. The technique is used to retrain or increase the activity of less-active tissues. The exercises were repeated 10-15 times with a two-second rest between them. The last step was integration, i.e., used for retraining and nerve and muscle function coordination through progressive functional movements [17] (Table 1).

In the Sharman exercise group, strengthening exercises were performed gradually from $30 \%-40 \%$ to $70 \%-80 \%$ of the study subjects' perceptual power using the Borg Rating of Perceived Exertion (RPE). The deep flexor muscles were strengthened by applying a biofeedback pressure device. First, the device was placed under the neck in a neutral position, and the pressure was adjusted to $20 \mathrm{mmHg}$. Before the test, the study subjects were trained to increase the pressure inside the bag to $3 \mathrm{mmHg}$ 


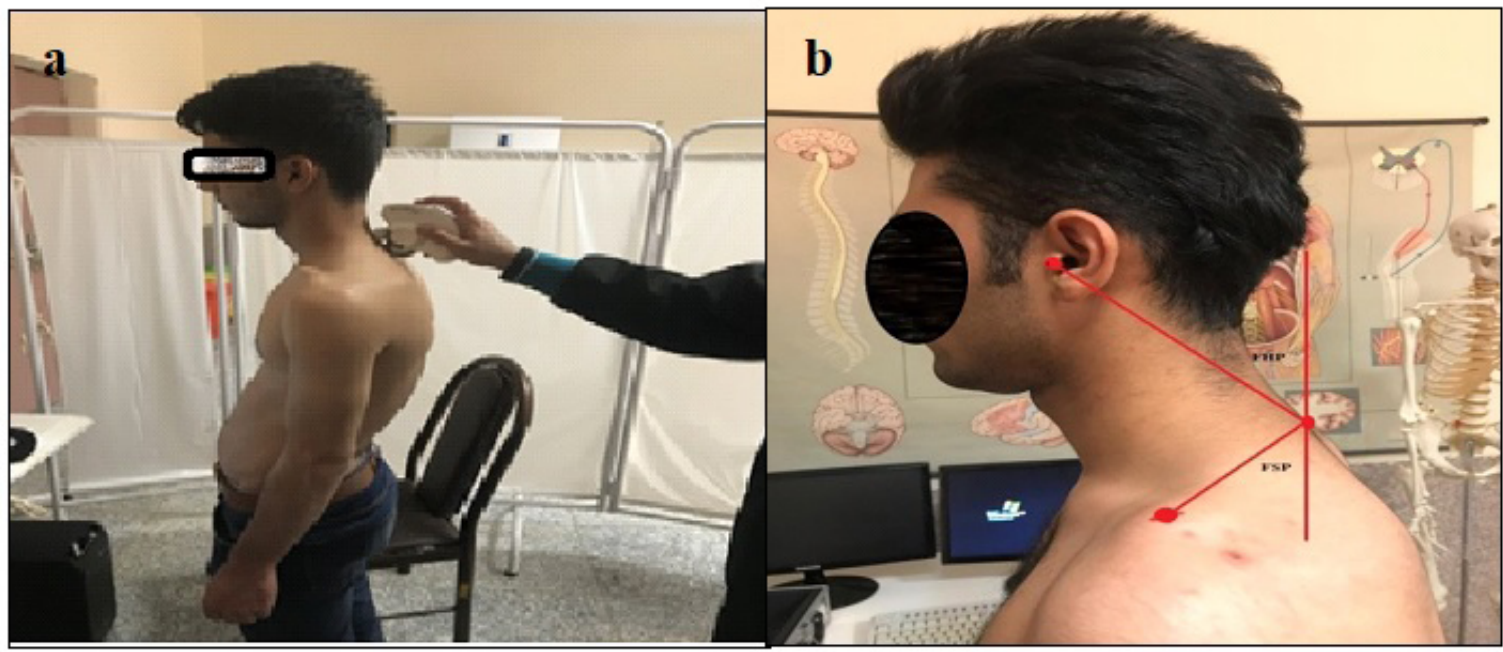

Figure 2. a. The evaluation of HKP with the spinal mouse device; b. Imaging method to detect FHP Iranian Rehabilitation \ournal

by contracting deep cervical flexors. The position was held for 10 seconds, followed by a 30 -second rest. Then, the research participants adjusted the pressure to 26 $\mathrm{mmHg}$ by contracting deep neck muscles. The process continued until reaching the final pressure level was applied (the highest-pressure change made by contracting the deep flexor muscles and maintaining the position for 10 seconds) [24]. Moreover, the strengthening exercises of thoracic extensors were performed at the end of the range of motion to reduce the mobility of the vertebrae. All selected exercises were purposefully designed based on the suggestions of previous research [25] (Table 2).

Data analysis was performed in SPSS v. 21 using the Shapiro-Wilk test (to ensure the normal distribution of the data), Independent Samples t-test (to compare the study groups respecting the homogeneity of demographic characteristics \& the study variables), Levene's test (to evaluate the homogeneity of variances), Paired Samples t-test, and one-way Analysis of Covariance (ANCOVA; by inserting the pretest as a covariate and to evaluate the effects
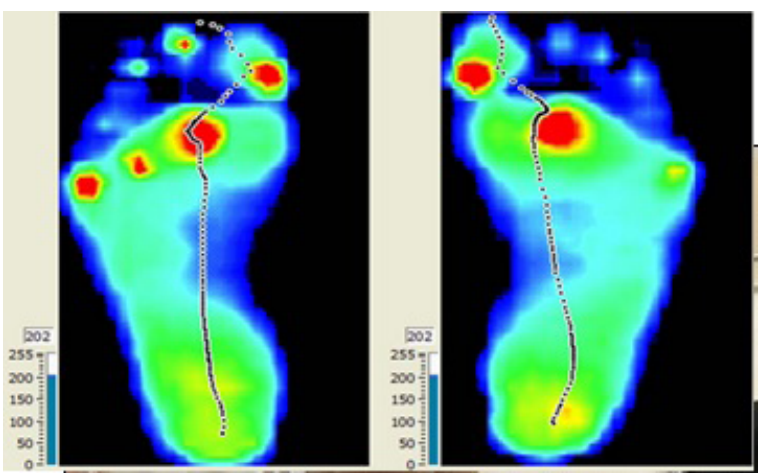

Iranian Rehabilitation \ourna

Figure 3. Foot pressure distribution in a software environment of the treatment protocols before and after the intervention). Furthermore, a P-value of 0.05 and a confidence interval of $95 \%$ were considered statistically significant.

\section{Results}

The Shapiro-Wilk test results were indicative of the data normal distribution $(\mathrm{P}>0.05)$. Additionally, Independent Samples t-test results revealed no significant difference between the study groups concerning the demographic characteristics (Table 3 ).

According to Paired Samples t-test, NASM exercises significantly affected the FHP correction (upper $=0.81$, lower=1.91, $\mathrm{t}=5.344, \mathrm{P}=0.0001$ ) and HKP (upper=6.46, lower=0.33, $\mathrm{t}=2.337, \mathrm{P}=0.032$ ). According to Paired Samples t-test results, Sahrmann corrective exercises also presented a significant effect on the FHP (upper $=0.81$, lower $=1.91, \mathrm{t}=5.344, \mathrm{P}=0.0001$ ) and HKP (upper=7.06, lower $=0.13, \mathrm{t}=2.225, \mathrm{P}=0.043$ ) correction. Furthermore, ANCOVA data suggested a significant difference between the research groups respecting the scores of decreased HKP angle $\left(\mathrm{F}_{1,27}=0.14, \mathrm{P}=0.0001\right)$ and $\mathrm{FHP}\left(\mathrm{F}_{1,27}=31.47, \mathrm{P}=0.0001\right)$ (Table 4).

ANCOVA results additionally revealed a significant difference between the study groups in the standard deviation of postural sways at the anterior-posterior direction $\left(\mathrm{F}_{1,27}=30.27, \mathrm{P}=0.0001\right)$; the standard deviation of postural sways at the medial-lateral direction $\left(\mathrm{F}_{1,27}=33.99\right.$, $\mathrm{P}=0.0001)$; COP path length $\left(\mathrm{F}_{1,27}=22.88, \mathrm{P}=0.0001\right)$; Minor Axis Length of COP sways $\left(\mathrm{F}_{1,27}=78.29, \mathrm{P}=0.0001\right)$, and Major Axis Length of COP sways $\left(\mathrm{F}_{1,27}=29.36\right.$, $\mathrm{P}=0.0001)$. Furthermore, partial Eta squared of 0.52 , $0.45,0.74$, and 0.52 presented a strong association be- 
Table 1. NASM exercises protocol for HKP and FHP used in an 8-week intervention program

\begin{tabular}{|c|c|c|c|c|}
\hline Techniques & & Muscles & Training & Load \\
\hline \multirow[t]{2}{*}{ Inhibitory techniques } & HKP & $\begin{array}{l}\text { Spine erectors- pectoralis muscles- } \\
\text { levator scapula-sternocleidomas- } \\
\text { toid- upper trapezius- latissimus } \\
\text { dorsi }\end{array}$ & $\begin{array}{l}\text { Released muscles by Foam roller } \\
\text { massage ball and massage by } \\
\text { hand }\end{array}$ & \multirow{2}{*}{$\begin{array}{l}\text { A set of } 5 \text { repetitions, } \\
30 \text { seconds to hold), } 20 \\
\text { seconds to rest (gradu- } \\
\text { ally increase to } 40 \text { sec). }\end{array}$} \\
\hline & FHP & $\begin{array}{l}\text { Spine erectors- levator scapula- ster- } \\
\text { nocleidomastoid- upper trapezius }\end{array}$ & $\begin{array}{l}\text { Released muscles by Foam roller } \\
\text { and massage- Finger pressure }\end{array}$ & \\
\hline \multirow{2}{*}{ Lengthening technique } & HKP & $\begin{array}{l}\text { levator scapula- sternocleidomas- } \\
\text { toid- upper trapezius- latissimus } \\
\text { dorsi- pectoralis major }\end{array}$ & $\begin{array}{l}\text { Sitting stretching exercises, stand- } \\
\text { ing stretching- Stretch in the cor- } \\
\text { ner of the wall }\end{array}$ & \multirow{2}{*}{$\begin{array}{l}\text { Repeat a set of } 4 \text { rep. } \\
\text { and hold for } 20 \text { sec- } \\
\text { onds, rest } 20 \text { seconds } \\
\text { (gradually increased to } \\
30 \text { sec). }\end{array}$} \\
\hline & FHP & $\begin{array}{l}\text { levator scapula- sternocleidomas- } \\
\text { toid- upper trapezius }\end{array}$ & $\begin{array}{l}\text { Sitting stretching exercises, stand- } \\
\text { ing stretching, supine stretching }\end{array}$ & \\
\hline \multirow{2}{*}{ Activation techniques } & HKP & $\begin{array}{l}\text { Deep neck flexor- neck erectors- } \\
\text { lower trapezius- spine erectors- } \\
\text { rhomboid-trapezius }\end{array}$ & $\begin{array}{l}\text { Kobra exercise, Scaption exercise, } \\
\text { Y and } W \text { exercise on a gym ball, } \\
\text { chin tuck }\end{array}$ & $\begin{array}{l}\text { Start with two sets of } \\
10 \text { rep., } 60 \text { seconds rest } \\
\text { (gradually sets were } \\
\text { increased to three and } \\
\text { repetitions to } 12 \text { ). }\end{array}$ \\
\hline & FHP & $\begin{array}{l}\text { Deep neck flexors- neck erectors- } \\
\text { lower trapezius- deep neck flexors- } \\
\text { spine erectors }\end{array}$ & $\begin{array}{l}\text { Kobra exercise, Scaption exercise, } \\
\text { Cervical-Thoracic Extensors (Re- } \\
\text { sisted Cervical Posterior Transla- } \\
\text { tion- Deep Cervical Flexors (Quad- } \\
\text { ruped Ball Chin Tucks) }\end{array}$ & $\begin{array}{l}\text { Start with two sets of } \\
10 \text { rep., } 60 \text { seconds rest } \\
\text { (gradually sets were } \\
\text { increased to three and } \\
\text { repetitions to } 12 \text { ). }\end{array}$ \\
\hline \multirow[t]{2}{*}{ Integration techniques } & HKP & $\begin{array}{l}\text { Using all the muscles to do the job } \\
\text { with proper activation and timing } \\
\text { between them }\end{array}$ & $\begin{array}{l}\text { Lunge and Step exercise with } T \\
\text { position and external rotation of } \\
\text { the hands- Single leg and both leg } \\
\text { squat with press above the head }\end{array}$ & \multirow{2}{*}{$\begin{array}{l}\text { Three sets of } 8 \text { rep., } \\
\text { rest between sets of } \\
60 \text { seconds(repetitions } \\
\text { gradually increased to } \\
\text { 12). }\end{array}$} \\
\hline & FHP & $\begin{array}{l}\text { Deep neck flexors- neck erectors } \\
\text { - lower trapezius- spine erectors- } \\
\text { rhomboid }\end{array}$ & $\begin{array}{l}\text { Ball Combo-Ball Combo ( } \mathrm{T} \text { posi- } \\
\text { tion)- Ball Combo (Cobra) }\end{array}$ & \\
\hline
\end{tabular}

Iranian Rehabilitation Journal

tween the pre- and post-intervention scores in the mentioned factors (Table 5).

According to ANCOVA results, there was no significant difference between the two interventions in terms of the standard deviation of plantar pressure symmetry index of the right and left feet $\left(\mathrm{F}_{1,27}=0.01, \mathrm{P}=0.91\right)$. However, the scores of plantar pressure symmetry index in the front and back of the right and left feet were significant $\left(\mathrm{F}_{1,27}=34.07, \mathrm{P}=0.0001\right)\left(\mathrm{F}_{1,27}=110.67, \mathrm{P}=0.000\right)$ after adjusted for the pretest. Furthermore, partial Eta squared of 0.55 and 0.88 demonstrated a strong relationship between the pre- and post-intervention scores in the mentioned factors (Table 6).

\section{Discussion}

The present study compared the effects of NASM and Sahrmann corrective exercises on HKP and FHP correction, plantar pressure distribution, and postural control in students with flexed postures. According to the obtained results, both corrective approaches significantly impacted all variables of plantar pressure distribution and postural control. Besides, both methods provided a significant effect on all variables of plantar pressure distribution, except for plantar pressure distribution between the two feet.

The obtained data indicated that 8 weeks of NASM exercises significantly decreased the angle of HKP and FHP, i.e., consistent with the results obtained by Abdolahzadeh et al. [26] and Roshani et al. [27]; they evaluated the effects of NASM exercises on individuals with the upper cross syndrome. Conventional corrective exercises focus on stretching shortened muscles and strengthening the weakened muscles. Moreover, researchers and therapists have recently emphasized chain reactions and using combined training, compared to separate exercises, to correct deformities [28].

The exercises considered based on the Sahrmann approach included pressure biofeedback application to strengthen deep cervical muscles and strengthening exercises for the extensor muscles of the back. After 8 weeks of corrective exercises designed based on the Sahrmann theory, we detected a decrease in HKP angle, i.e., congruent with the results obtained by Kang et al. and Gupta et al.; they assessed the impact of corrective exercises with pressure biofeedback on the increased angle of FHP. Accordingly, they reported a significant decrease 
Table 2. Sahrmann corrective exercises protocol for HKP used in an 8-week intervention program

\begin{tabular}{|c|c|c|c|}
\hline Exercises & Target & Load & Equipment \\
\hline Prone trunk lift to neutral & $\begin{array}{l}\text { Thoracic, lumbar, and hip extensor } \\
\text { strengthening }\end{array}$ & $\begin{array}{l}\text { The maintenance time of each move gradu- } \\
\text { ally increased from } 5 \text { to } 15 \text { seconds while the } \\
\text { number of repetitions of each set increased } \\
\text { from } 8 \text { to } 12 \text { moves }\end{array}$ & $\begin{array}{c}\text { Cuff } \\
\text { weights }\end{array}$ \\
\hline $\begin{array}{l}\text { Side-lying thoracic rotation/ } \\
\text { extension }\end{array}$ & $\begin{array}{l}\text { Thoracic extension and rotation with } \\
\text { scapulothoracic retraction/depression } \\
\text { strengthening and mobility in extension } \\
\text { and rotation }\end{array}$ & $\begin{array}{l}\text { Start with two sets of } 10 \text { repetitions, } 60 \text { sec- } \\
\text { onds rest (gradually the sets were promoted } \\
\text { to three and repetitions to } 12 \text { ) }\end{array}$ & Thera-Band \\
\hline $\begin{array}{l}\text { Ball Combo- Ball Combo(T } \\
\text { position)- Ball Combo(Cobra) }\end{array}$ & $\begin{array}{l}\text { Thoracic extension with scapulothoracic } \\
\text { retraction/depression strengthening }\end{array}$ & $\begin{array}{l}\text { Start with two sets of } 10 \text { repetitions, } 60 \text { sec- } \\
\text { onds rest (gradually the sets were promoted } \\
\text { to three and repetitions to } 12 \text { ) }\end{array}$ & $\begin{array}{l}\text { Thera-Band } \\
\text { Dambulla }\end{array}$ \\
\hline Quadruped arm and leg lift & $\begin{array}{l}\text { The stability of trunk with mobility of } \\
\text { extremities; strengthen lower trapezius, } \\
\text { spinal extensor, multifidus, and trans- } \\
\text { verse abdominal muscles }\end{array}$ & $\begin{array}{l}\text { Start with two sets of } 10 \text { repetitions, } 60 \text { sec- } \\
\text { onds rest (gradually the sets were promoted } \\
\text { to three and repetitions to } 12 \text { ) }\end{array}$ & $\begin{array}{l}\text { Cuff } \\
\text { weights }\end{array}$ \\
\hline $\begin{array}{l}\text { Side-lying hip abduction/ex- } \\
\text { ternal rotation }\end{array}$ & $\begin{array}{l}\text { Strengthen gluteus medius muscle for } \\
\text { stability instance }\end{array}$ & $\begin{array}{l}\text { Start with two sets of } 10 \text { repetitions, } 60 \mathrm{sec}- \\
\text { onds rest (gradually the sets were promoted } \\
\text { to three and repetitions to } 12 \text { ) }\end{array}$ & $\begin{array}{l}\text { Cuff } \\
\text { weights }\end{array}$ \\
\hline
\end{tabular}

Iranian Rehabilitation Journal

in the angle after the intervention $[29,30]$. According to Sahrmann's theory, the deformity can be corrected by correcting agonist muscle stiffness relative to the antagonist's muscles. In the current research, the pressure biofeedback exercises created a balance in muscle stiffness and decreased FHP. Kang et al. reported similar results, suggesting that exercises with pressure biofeedback devices further improved the deep cervical muscles, compared to conventional exercises [10]. Furthermore, a major part of the current corrective protocol was dedicated to strengthening the spinal erector muscles, which improved the thoracic spine's position by enhancing the strength of the scapular retractors and stabilizers [31].
According to the obtained results, Sahrmann exercises were more effective on the variables of plantar pressure distribution, compared to the NASM program. This higher effectiveness of Sahrmann exercises could be attributed to two theories. First, proprioception function is disturbed by stretching the shortened muscles; it leads to impaired feedforward and feedback motor control, change in muscle tightness, and the dysfunction of the sensorimotor system [32]. The second theory highlights the effectiveness of Sahrmann exercises on balancing muscle stiffness. Muscle stiffness is often discussed along with muscle tone and elasticity. It is due to the determining role of this issue in responding to perturba-

Table 3. The demographic characteristics of the study participants

\begin{tabular}{|c|c|c|c|}
\hline \multirow{2}{*}{ Variables } & \multicolumn{2}{|c|}{ Mean $\pm S D$} & \multirow{2}{*}{$\mathbf{P}^{*}$} \\
\hline & NASM Group $(n=15)$ & Sahrmann Group (n=15) & \\
\hline Age (y) & $21.66 \pm 2.05$ & $19.37 \pm 5.81$ & 0.23 \\
\hline Height $(\mathrm{cm})$ & $175.13 \pm 6.35$ & $177.60 \pm 7.77$ & 0.34 \\
\hline Weight (kg) & $73.26 \pm 7.80$ & $77.53 \pm 7.95$ & 0.15 \\
\hline $\mathrm{BMI}\left(\mathrm{kg} / \mathrm{m}^{2}\right)$ & $23.90 \pm 2.48$ & $24.58 \pm 2.00$ & 0.41 \\
\hline HKP (degree) & $48.40 \pm 11.96$ & $47.20 \pm 9.81$ & 0.76 \\
\hline FHP (degree) & $51.66 \pm 1.69$ & $51.56 \pm 1.42$ & 0.86 \\
\hline
\end{tabular}

Iranian Rehabilitation Journal

* According to the independent t-test, no significant difference was observed between the two groups regarding the demographic characteristics and angle of HKP and FHP.

SD; Standard Deviation; kg; kilogram; BMI: Body Mass Index; FHP; Forward Head Posture; HKP: Hyperkyphosis Posture, NASM; National Academy of Sports Medicine. 
Table 4. ANCOVA results concerning the angle of hyperkyphosis and forward head posture

\begin{tabular}{|c|c|c|c|c|}
\hline Variables & Groups & Post-tests (Adjusted by Pre-tests), Mean \pm SD & $\mathbf{F}$ & $\mathbf{P}$ \\
\hline \multirow{3}{*}{ HKP } & NASM & $47.7 \pm 1.36$ & \multirow{3}{*}{56.61} & \multirow{3}{*}{$0.0001 * *$} \\
\hline & & & & \\
\hline & Sahrmann & $46.33 \pm 1.38$ & & \\
\hline \multirow{3}{*}{ FHP } & NASM & $50.24 \pm 0.44$ & \multirow{3}{*}{31.47} & \multirow{3}{*}{$0.0001 * *$} \\
\hline & & & & \\
\hline & Sahrmann & $46.64 \pm 0.64$ & & \\
\hline
\end{tabular}

Iranian Rehabilitation Journal

"P<0.01; HKP: Hyperkyphosis Posture; FHP: Forward Head Posture; NASM: National Academy of Sports Medicine; SD: Standard Deviation

tions and maintaining joint stability and decreasing the risk of injuries [33]. Tighter muscles are more resistant to lengthening and have more tone. Besides, they are a more effective dynamic deterrent against joint displacement and posture control [34]. Accordingly, these exercises reduce the electromechanical delay of the postural muscles and increase reflex activity. This increase in muscle stiffness and tone probably significantly influences joint stability and acts as the first protective mechanism against abnormal forces applied to the joint [34]. Mousavi et al. reported that HKP and FHP lead to shifting of the center of pressure forward and decreased pressure in the heel and the middle part of the foot, i.e., consistent with our findings [15]. According to previous studies and the output of the plantar pressure distribution device, the static plantar pressure distribution was greater at the back of the feet, compared to the front of the feet. Tuna et al. reported a mean static pressure of $64.24 \%$ in the back of the feet and $35.87 \%$ in the front of the feet [35]; however, Cavanagh et al. reported respectively $66 \%$ and $33 \%$ for the back and front of the feet of healthy subjects [36]. Therefore, the plantar pressure distribution significantly decreased with a reduction in the angle of HKP and FHP, i.e., in line with our findings. Despite a significant correlation between plantar pressure distribution and postural control, COP and loading seemed to have changed from the anterior to the posterior part; loading increased in the posterior part, compared

Table 5. ANCOVA results for postural control variables

\begin{tabular}{|c|c|c|c|c|c|}
\hline Variables & Groups & $\begin{array}{c}\text { Posttest Scores } \\
\text { (Adjusted by Pretest Scores), Mean } \pm \text { SD }\end{array}$ & $\mathbf{F}$ & $\eta^{2}$ & $\mathbf{P}$ \\
\hline Anterior-Posterior postural sways & $\begin{array}{c}\text { NASM } \\
\text { Sahrmann }\end{array}$ & $\begin{array}{l}16.73 \pm 0.24 \\
18.68 \pm 0.24\end{array}$ & 30.27 & 0.52 & $0.0001^{* *}$ \\
\hline Medial-Lateral postural sways & $\begin{array}{c}\text { NASM } \\
\text { Sahrmann }\end{array}$ & $\begin{array}{l}15.31 \pm 0.20 \\
13.61 \pm 0.20\end{array}$ & 33.99 & 0.55 & $0.0001^{* *}$ \\
\hline COP path length & $\begin{array}{c}\text { NASM } \\
\text { Sahrmann }\end{array}$ & $\begin{array}{l}675.71 \pm 30.01 \\
592.78 \pm 29.87\end{array}$ & 22.88 & 0.45 & $0.0001 * *$ \\
\hline Minor Axis Length & $\begin{array}{c}\text { NASM } \\
\text { Sahrmann }\end{array}$ & $\begin{array}{l}32.33 \pm 0.27 \\
28.82 \pm 0.27\end{array}$ & 78.29 & 0.74 & $0.0001^{* *}$ \\
\hline Major Axis Length & $\begin{array}{c}\text { NASM } \\
\text { Sahrmann }\end{array}$ & $\begin{array}{l}110.34 \pm 8.24 \\
96.16 \pm 9.08\end{array}$ & 29.36 & 0.52 & $0.0001^{* *}$ \\
\hline COP area & $\begin{array}{c}\text { NASM } \\
\text { Sahrmann }\end{array}$ & $\begin{array}{l}382.33 \pm 75.16 \\
397.83 \pm 71.11\end{array}$ & 0.21 & 0.88 & $0.0001^{* *}$ \\
\hline
\end{tabular}

** P<0.01; COP: Center of Pressure; SD: Standard Deviation; NASM: National Academy of Sports Medicine. 
Table 6. ANCOVA results concerning plantar pressure symmetry index

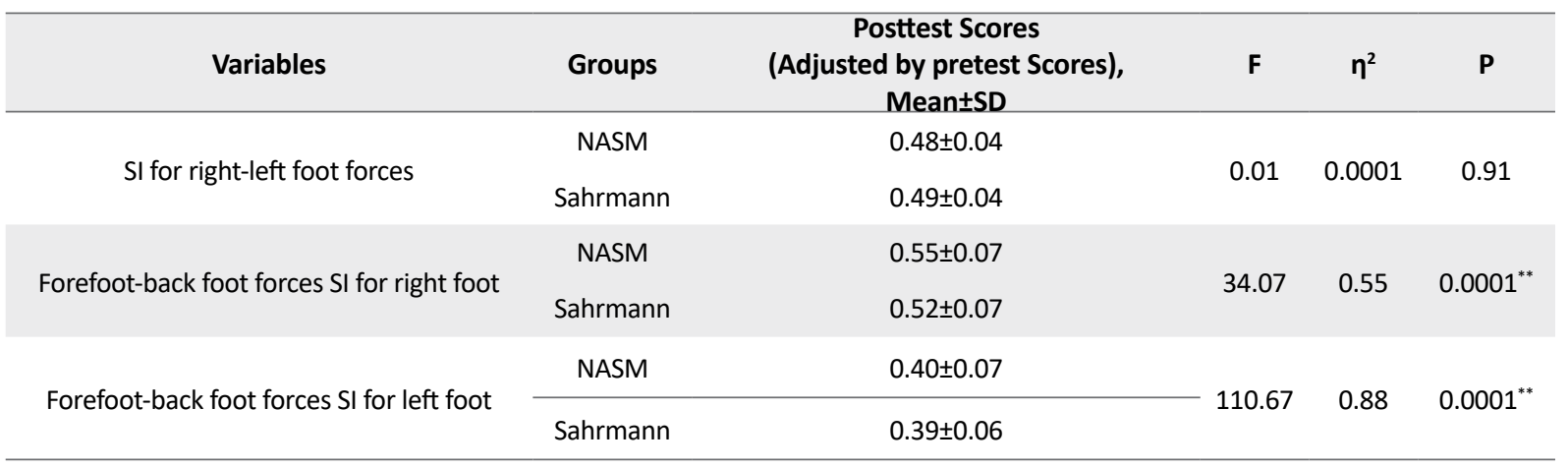

"P<0.01; SD: Standard Deviation; SI: Symmetry Index

Iranian Rehabilitation Journa

to the anterior, with correcting the spinal curvature and reducing postural sways [37]. The lack of the effectiveness of corrective protocols on the plantar pressure distribution between the two feet might be related to the dominant foot of the study subjects; the weight of limbs was applied to the superior foot [38]. There were some limitations with the present study, such as its small sample size, participants were restricted to the male gender, and we lacked a control group. It is recommended that the effect of corrective protocols on different kinematic and kinetic factors be assessed during various daily and functional tasks in future studies.

\section{Conclusion}

According to the present study results, both provided corrective methods decreased the angle of HKP and FHP as well as postural fluctuations. However, Sahrmann exercises were more effective in the improvement of postural control and foot pressure distribution, compared to NASM exercises. It could be due to its ability to modulate muscle stiffness, regulate muscle tone-tension, and reduce electromechanical delay. Therefore, Sahrmann exercises presented further efficiency in improving foot pressure distribution variables, compared to NASM exercises.

\section{Ethical Considerations}

\section{Compliance with ethical guidelines}

The research proposal was approved by the RAZI University Ethics Committee (IR.RAZI. REC.1398.006) and registered at the clinical trial center (IRCT20190426043377N2). Moreover, the clinical trial was conducted per the Declaration of Helsinki, 2008.
Funding

This article was extracted from a MSc.thesis. This research was financially supported by Razi University.

\section{Authors' contributions}

Both authors contributed equally in preparing all parts of the research.

\section{Conflict of interest}

The authors declared no conflicts of interest.

\section{Acknowledgments}

We extend our gratitude to all of the participants, and corrective exercises lab directors, and the lab specialist for assisting us in performing the research.

\section{References}

[1] Jeong H-J, Kim B-J. The effect of thoracic joint mobilization on the changes of the thoracic kyphosis angle and static and dynamic balance. Biomedical Science Letters. 2019; 25(2):14958. [DOI:10.15616/BSL.2019.25.2.149]

[2] Dockrell S, Bennett K, Culleton-Quinn E. Computer use and musculoskeletal symptoms among undergraduate university students. Computers \& Education. 2015; 85:102-9. [DOI:10.1016/j.compedu.2015.02.001]

[3] Seidi F, Rajabi R, Ebrahimi I, Alizadeh MH, Minoonejad H. The efficiency of corrective exercise interventions on thoracic hyperkyphosis angle. Journal of Back and Musculoskeletal Rehabilitation. 2014; 27(1):7-16. [DOI:10.3233/BMR-130411] [PMID]

[4] Tarasi Z, Rajabi R, Minoonejad H, Shahrbanian S. The effect of spine strengthening exercises and posture training on functional thoracic hyper kyphosis in young individuals. Jour- 
nal of Advances in Medical and Biomedical Research. 2019; 27(121):23-31. [DOI:10.30699/jambs.27.121.23

[5] Page P, Frank C, Lardner R. Assessment and treatment of muscle imbalance: The Janda approach. $1^{\text {th }}$ ed. Champaign: Human kinetics; 2009. https://www.amazon.com/ Assessment-Treatment-Muscle-Imbalance-Approach/ dp/0736074007

[6] Blum CL. The many faces of forward head posture: The importance of differential diagnosis. Cranio: The Journal of Craniomandibular Practice. 2019; 37(3):143-6. [DOI:10.1080/0886 9634.2019.1594003] [PMID]

[7] Hajihosseini E, Norasteh AA, Shamsi A, Daneshmandi H. [The effect of 6 weeks strength training, stretching and comprehensive corrective exercises on forward head incorrect posture (Persian)]. Journal of Modern Rehabilitation. 2016 9(5):38-48. http:/ / mrj.tums.ac.ir/article-1-5382-en.html

[8] Sheikhhoseini R, Shahrbanian S, Sayyadi P, O'Sullivan K. Effectiveness of therapeutic exercise on forward head posture: A systematic review and meta-analysis. Journal of Manipulative and Physiological Therapeutics. 2018; 41(6):530-9. [DOI:10.1016/j.jmpt.2018.02.002] [PMID]

[9] Kendall FP, Provance P, McCreary EK. Muscles, testing and function: With posture and pain. $4^{\text {th }}$ ed. Philadelphia: Lippincott Williams \& Wilkins; 1993. https://www.amazon.com/ Muscles-Testing-Function-Posture-Pain/dp/0683045768

[10] Kang J-H, Park R-Y, Lee S-J, Kim J-Y, Yoon S-R, Jung K-I. The effect of the forward head posture on postural balance in long time computer based worker. Annals of Rehabilitation Medicine. 2012; 36(1):98-104. [DOI:10.5535/arm.2012.36.1.98] [PMID] [PMCID]

[11] Silva AG, Johnson MI. Does forward head posture affect postural control in human healthy volunteers? Gait \& Posture. 2013; 38(2):352-3. [DOI:10.1016/j.gaitpost.2012.11.014] [PMID]

[12] Roghani T, Zavieh MK, Manshadi FD, King N, Katzman W. Age-related hyperkyphosis: Update of its potential causes and clinical impacts-narrative review. Aging Clinical and Experimental Research. 2017; 29(4):567-77. [DOI:10.1007/ s40520-016-0617-3] [PMID] [PMCID]

[13] Navega MT, Furlanetto MG, Lorenzo DM, Morcelli MH, Tozim BM. Effect of the Mat Pilates method on postural balance and thoracic hyperkyphosis among elderly women: a randomized controlled trial. Revista Brasileira de Geriatria e Gerontologia. 2016; 19(3):465-72. [DOI:10.1590/180998232016019.150022

[14] Jang H-J, Hughes LC, Oh D-W, Kim S-Y. Effects of corrective exercise for thoracic hyperkyphosis on posture, balance, and well-being in older women: A double-blind, groupmatched design. Journal of Geriatric Physical Therapy. 2019; 42(3):E17-27. [DOI:10.1519/JPT.0000000000000146] [PMID]

[15] Mousavi ME, Bani MA, Aboutorabi A, Zare H, Head J, Yeghaneh MM, et al. The effect of a semi-rigid thoracolumbosacral orthosis (TLSO) on foot pressure in elderly subjects presenting with spinal hyperkyphosis. Disability and Rehabilitation: Assistive Technology. 2020; 15(2):205-10. [DOI 10.1080/17483107.2018.1555289]

[16] Kim E-K, Kim S-G. Forward head posture (FHP) angle and plantar pressure resulting from oscillatory stimulation training of the shoulder joint: A randomized controlled trial.
Journal of Back and Musculoskeletal Rehabilitation. 2019; 32(1):37-42. [DOI:10.3233/BMR-160748] [PMID]

[17] Clark M, Lucett S, National Academy of Sports Medicine. NASM essentials of corrective exercise training. Philadelphia: Lippincott Williams \& Wilkins; 2010. https://books google.com/books/about/NASM_Essentials_of_Corrective_Exercise_T.html?id=tZGIM2xzeSwC

[18] Sahrmann S. Diagnosis and treatment of movement impairment syndromes-E-Book. Netherlands: Elsevie Health Sciences; 2013. https://books.google.com/books/ about/Diagnosis_and_Treatment_of_Movement_Impa. $h t m l$ id $=x e Z O A Q A A Q B A J$

[19] Letafatkar A, Rabiei P, Alamooti G, Bertozzi L, Farivar N, Afshari M. Effect of therapeutic exercise routine on pain, disability, posture, and health status in dentists with chronic neck pain: A randomized controlled trial. International Archives of Occupational and Environmental Health. 2020; 93(3):281-90. [DOI:10.1007/s00420-019-01480-x] [PMID]

[20] Quek J, Pua Y-H, Clark RA, Bryant AL. Effects of thoracic kyphosis and forward head posture on cervical range of motion in older adults. Manual Therapy. 2013; 18(1):65-71. [DOI:10.1016/j.math.2012.07.005] [PMID]

[21] Rahmani P, Shahrokhi H, Daneshmandi H. [The investigation of spinal abnormalities \& balance and relation between them in patients with Down syndrome (Persian)]. Modern Rehabilitation. 2014; 8(4):63-9. http://mrj.tums.ac.ir/article1-5175-en.htm

[22] Fadaee E, Seidi F, Rajabi R. [The spinal mouse validity and reliability in measurement of thoracic and lumbar vertebral curvatures (Persian)]. Journal of Shahrekord Uuniversity of Medical Sciences. 2017; 19(1):137-47. http://eprints.skums. ac.ir/id/eprint/ 625

[23] Braun BJ, Veith NT, Hell R, Döbele S, Roland M, Rollmann $\mathrm{M}$, et al. Validation and reliability testing of a new, fully integrated gait analysis insole. Journal of Foot and Ankle Research. 2015; 8:54. [DOI:10.1186/s13047-015-0111-8] [PMID] [PMCID]

[24] Raju AS, Apparao P, Swamy G, Chaturvadi P, Mounika RG. A comparative study on deep cervical flexors training and neck stabilization exercises in subjects with chronic neck pain. Indian Journal of Physiotherapy \& Occupational Therapy. 2019; 13(2). [DOI:10.5958/0973-5674.2019.00035.2]

[25] Katzman WB, Vittinghoff E, Kado DM, Schafer AL, Wong SS, Gladin A, et al. Study of hyperkyphosis, exercise and function (SHEAF) protocol of a randomized controlled trial of multimodal spine-strengthening exercise in older adults with hyperkyphosis. Physical Therapy. 2016; 96(3):371-81. [DOI:10.2522/ptj.20150171] [PMID] [PMCID]

[26] Abdolahzad M, Daneshmandi H. [The effect of an 8-week NASM corrective exercise program on upper crossed syndrome (Persian)]. Journal of Sport Biomechanics. 2019; 5(3):156-67. [DOI:10.32598/biomechanics.5.3.3]

[27] Roshani S, Mahdavinejad R, Ghanizadehesar N. [The effect of a NASM-based training protocol on upper cross syndrome in paraplegia spinalcord injury patients (Persian)]. Scientific Journal of Ilam University of Medical Sciences. 2018; 25(6):7385. [DOI:10.29252/sjimu.25.6.73]

[28] Kamali M, Ghasemi B, Moradi M, Bagherian Dehkordi S. [Comparing the effect of two kinds of the traditional and the NASM corrective exercises training protocols on the correc- 
tion of hyperlordosis in female students (Persian)]. Journal of Research in Rehabilitation Sciences. 2015; 11(2):155-63. https://iranjournals.nlai.ir/handle/123456789/760333

[29] Kang DY. Deep cervical flexor training with a pressure biofeedback unit is an effective method for maintaining neck mobility and muscular endurance in college students with forward head posture. Journal of Physical Therapy Science. 2015; 27(10):3207-10. [DOI:10.1589/jpts.27.3207] [PMID] [PMCID]

[30] Gupta BD, Aggarwal S, Gupta B, Gupta M, Gupta N. Effect of deep cervical flexor training vs. conventional isometric training on forward head posture, pain, neck disability index in dentists suffering from chronic neck pain. Journal of Clinical and Diagnostic Research: JCDR. 2013; 7(10):2261-4. [DOI:10.7860/JCDR/2013/6072.3487] [PMID] [PMCID]

[31] Singla D, Veqar Z. Association between forward head, rounded shoulders, and increased thoracic kyphosis: A review of the literature. Journal of Chiropractic Medicine. 2017; 16(3):220-9. [DOI:10.1016/j.jcm.2017.03.004] [PMID] [PMCID]

[32] Röijezon U, Clark NC, Treleaven J. Proprioception in musculoskeletal rehabilitation. Part 1: Basic science and principles of assessment and clinical interventions. Manual Therapy. 2015; 20(3):368-77. [DOI:10.1016/j.math.2015.01.008] [PMID]

[33] Bruhn S, Kullmann N, Gollhofer A. The effects of a sensorimotor training and a strength training on postural stabilization, maximum isometric contraction and jump performance. International Journal of Sports Medicine. 2004; 25(1):56-60. [DOI: 10.1055/s-2003-45228]

[34] Prentice WE. Rehabilitation techniques for sports medicine and athletic training. Boston: McGraw-Hill; 2004. https:// search.library.wisc.edu/catalog/9910018157502121/cite

[35] Tuna H, Yildiz M, Celtik C, Kokino S. Static and dynamic plantar pressure measurements in adolescents. Acta Orthopaedica et Traumatologica Turcica. 2004; 38(3):200-5. [PMID]

[36] Cavanagh PR, Rodgers MM, liboshi A. Pressure distribution under symptom-free feet during barefoot standing. Foot \& Ankle. 1987; 7(5):262-78. [DOI:10.1177/107110078700700502] [PMID]

[37] Levine D, Richards J, Whittle MW. Whittle's gait analysisE-Book. $5^{\text {th }}$ ed. Netherlands: Elsevier Health Sciences; 2012. https://books.google.com/books/about/Whittle_s_Gait_ Analysis_E_Book.html?id=xZbQAQAAQBAJ\&source $=\mathrm{kp}$ _ book_description

[38] Whittle MW. Gait analysis: An introduction. Amsterdam: Elsevier Science; 2014. https://www.google.com/books/ edition/Gait_Analysis/dYHiBQAAQBAJ?hl=en 
This Page Intentionally Left Blank 